\title{
The Emergence of Language in the Hominin Lineage: Perspectives from Fossil Endocasts
}

\author{
Amélie Beaudet ${ }^{1,2 *}$ \\ ${ }^{1}$ School of Geography, Archaeology and Environmental Studies, University of the Witwatersrand, Johannesburg, \\ South Africa, ${ }^{2}$ Department of Anatomy, University of Pretoria, Pretoria, South Africa
}

Keywords: paleoneurology, endocasts, Australopithecus, sulcal patterns, Broca's area

\section{FROM ENDOCASTS TO BRAINS}

Since brain does not fossilize, brain endocast (i.e., replica of the inner surface of the braincase, Figure 1) constitutes the only direct evidence for reconstructing hominin brain evolution (Holloway, 1978; Holloway et al., 2004a). In this context, paleoneurology has suffered from strong limitations due to the fragmentary nature of the fossil record and the absence of any information regarding subcortical elements in extinct taxa. Additionally, variation in brain shape and organization (and in the corresponding endocast) is technically difficult to capture, as stated by Bruner (2017a, p. 64): "[...] the smooth and blurred geometry of the brain, its complex and complicated mechanisms, and its noticeable individual variability make any research associated with its morphology very entangled and difficult to develop within fixed methodological approaches." An emblematic example might be the reluctance of paleoneurologists to consider the sulcal imprints visible on the endocranial surface because of the substantial uncertainties in describing such features in fossil specimens and related debates (e.g., the lunate sulcus in the Taung child's endocast; Falk, 1980a, 2009, 2014; Holloway, 1981a; Holloway et al., 2004b). In 1987, Tobias even came to the conclusion that "The recognition of specific cerebral gyri and sulci from their

OPEN ACCESS

Edited by:

Antonio Benítez-Burraco, University of Huelva, Spain

Reviewed by:

Simon Neubauer, Max Planck Institute for Evolutionary Anthropology (MPG), Germany Ralph L. Holloway,

Columbia University, United States

*Correspondence: Amélie Beaudet beaudet.amelie@gmail.com

Received: 22 July 2017 Accepted: 09 August 2017 Published: 23 August 2017

Citation:

Beaudet A (2017) The Emergence of Language in the Hominin Lineage: Perspectives from Fossil Endocasts.

Front. Hum. Neurosci. 11:427.

doi: 10.3389/fnhum.2017.00427 impressions on an endocast is a taxing, often subjective and even invidious undertaking which arouses much argumentation" (p. 748). However, in conjunction with a conceptual shift toward a more comprehensive overview of hominin brain evolution (e.g., reconsideration of the "cerebral rubicon" characterizing the human brain, Falk, 1980b; Holloway, 1983), continuous discoveries of new fossil material and recent analytical developments are progressively improving and refining our knowledge about the human neural evolutionary history. In particular, paleoneurology is producing new evidence for reconstructing the timing and mode of the emergence of crucial functions, such as language.

\section{WHAT FOSSIL ENDOCASTS CAN TELL US: CORTICAL ORGANIZATION AND SHAPE}

When the neurocranium is filled with sediment during the fossilization process, information about brain morphology and organization may be recorded as a natural endocast (e.g., Figure 1D). For fossil specimens not preserving a natural endocast, it is possible to generate a virtual imprint of the endocranial surface (Figures 1A-C). Within the limitations discussed above, the endocast provides evidence for tracking both structural and morphological changes in brain within the hominin lineage (Holloway, 1978; Holloway et al., 2004a; Zollikofer and Ponce de León, 2013). In this context, fossil endocasts can potentially deliver critical data for identifying cerebral reorganization with implications for speech capacity. In particular, the frontal lobe is involved in crucial functions suggested to be specific to extant humans. Among them, language has been invariably linked to the Broca's cap configuration and the lateral aspect of the frontal lobes has been consequently largely 

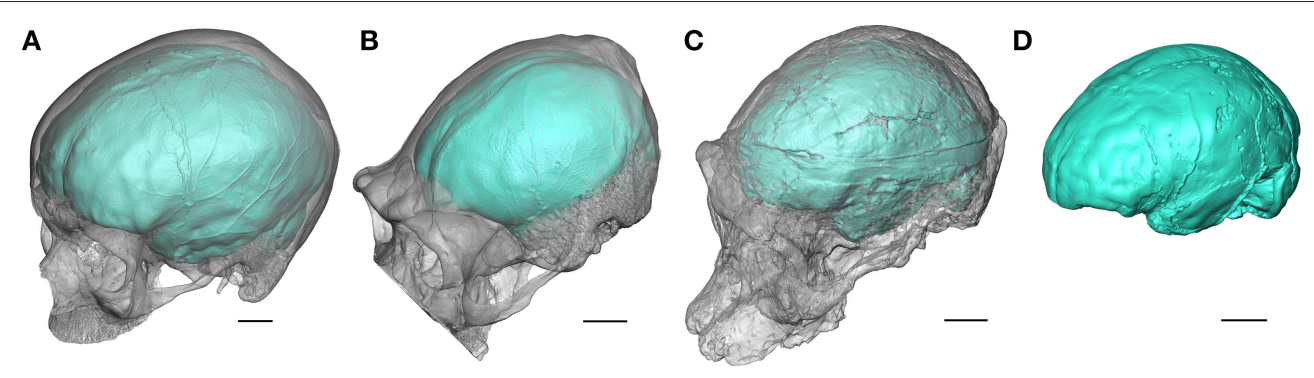

FIGURE 1 | Oblique views of the endocasts of an extant human (A), an extant chimpanzee (B), and of the Australopithecus africanus specimens Sts 5 (C), and Sts 60 (D) from Sterkfontein (South Africa). Sts 60 is a natural endocast associated to the fragmented cranium TM 1511. The braincase is rendered semi-transparent. Scale bars: $2 \mathrm{~cm}$.

explored in the hominin fossil record. The human-like configuration of the Broca's area has long been acknowledged to emerge concomitantly with the genus Homo (Falk, 1983; Tobias, 1987; see also the earliest descriptions of the Broca's cap in fossil humans, e.g., Kappers, 1929; Connolly, 1950). However, besides being largely questioned in the extant primate taxa (rev. in Bruner, 2017b), recent reinvestigation of the fossil record has revealed a more complex history of the reorganization of the frontal lobes, and more particularly of the inferior frontal gyrus and Broca's cap, deeply rooted in the early representatives of the hominin lineage.

In terms of structural organization, the identification of two differential patterns in the extant ape and human frontal lobes, characterized, respectively, by the presence of the fronto-orbital sulcus and of the horizontal and ascending branches of the lateral fissure, was previously considered as an effective trait for identifying the derived condition of the Broca's cap in the fossil record (rev. in Falk, 2014). In extant humans, even if the correspondence between the sulcal pattern and cytoarchitectonic areas is questioned (Amunts et al., 1999), the two rami of the lateral fissure delineate the Brodmann's areas 44 and 45 involved in language production and comprehension (Falk, 2014). Within this framework, while the ape-like pattern was described in the South African Australopithecus hypodigm, the endocasts of the earliest human representatives were suggested to be closer to the extant human condition (Falk, 1983, 2014; Tobias, 1987). However, this structural feature turned out to be more complex than previously thought. In particular, the high-resolution virtual investigation of the Australopithecus sediba endocast (MH 1) adds further complexity to this purported dichotomy since this specimen combines a chimpanzee-like sulcal pattern with evidence of shape reorganization (Carlson et al., 2011). Similarly, Holloway et al. (2004a) thoroughly explored the fossil hominin record and reported occurrences of shape frontal asymmetries at the level of the Broca's cap in early hominins (e.g., Sts 5), confirming that this configuration is not confined to Homo (Tobias, 1987). A leftward asymmetry of the Broca's cap is commonly reported in extant humans and considered to be functionally relevant for speech capacities, even if still largely debated (rev. in Keller et al., 2009). Imaging techniques and 3D modeling of the virtual endocast supported the assumption of the presence of frontal asymmetries in non-human fossil hominins by mapping shape asymmetries (Braga and Thackeray,
2007; Beaudet et al., 2014). Moreover, landmark-based analyses of the asymmetries of the third frontal convolution in fossil and extant hominids demonstrated a gradual increase in the degree of expression of asymmetries in the human lineage and emphasize the need of not only describing the occurrence but also quantifying the "magnitude" of endocranial asymmetries (Balzeau et al., 2014).

Given that the latest studies challenged our previous thoughts on the emergence of the human-like configuration of the frontal lobes (see also Beaudet and Bruner, in press), the next step would be to reconsider the available evidence from a new perspective, notably by overcoming current limitations in paleoneurology. The development of new imaging techniques, such as phase contrast X-ray synchrotron microtomography (e.g., Carlson et al., 2011) or neutron microtomography (e.g., Beaudet et al., 2016a; Zanolli et al., 2017), pushes further the practical limits inherent to the non-invasive investigation of endostructural features in fossil specimens. The major difficulty in discussing the sulcal pattern in endocasts, and the configuration of critical cortical areas such as the Broca's cap, lies in the absence of reliable protocols for automatically identifying the furrows on the fossil endocranial surface, as currently performed on the MRIs of extant human brains (e.g., Fischer et al., 2012). However, recent efforts in applying computer-assisted approaches for automatic sulci detection in fossil primate endocasts have paved the way for future methodological developments (Beaudet et al., 2016b). Similarly, the successful application of landmark-free deformation-based models for exploring fossil primate endocranial surfaces (e.g., Durrleman et al., 2012; Beaudet et al., 2016b; Beaudet and Bruner, in press) and assessing endocranial asymmetries (Kitchell, 2017) are providing encouraging perspectives for applications in paleoneurology. As a concrete example of future applications, since the extant human Broca's cap is characterized by a particular morphoarchitecture (i.e., combination of specific sulcal organization and pattern of shape asymmetries of the inferior frontal gyrus), the construction of a statistical model (e.g., atlas) reporting 3D variations of the sulcal pattern (as previously performed in 2D by Connolly, 1950) and external morphology of this area in extant hominids would allow to automatically characterize the fossil condition and test critical hypothesis (e.g., reorganization of the inferior frontal gyrus in Australopithecus). By integrating the intra-specific 
morphological variability and provide objective data, such a protocol would represent a valuable tentative for overcoming serious limitations in paleoneurology. Consequently, we might predict that fresh evidence will certainly emerge from the systematic reinvestigation of the fossil record with the assistance of imaging techniques and 3D modeling methods.

\section{LOOKING FOR FURTHER EVIDENCE}

Speech capacity cannot be appropriately inferred only from the cerebral condition, therefore hypotheses aiming at reconstructing the timing and mode of emergence of language in the hominin lineage should seek to combine various lines of evidence. The endocast is the only direct proxy for reconstructing the fossil neural condition and cerebral capacities in extinct species. However, additional cranial regions might contribute to understand the development of language capacity in the human evolution. As for instance, the petrous bone is frequently preserved in the fossil record and imaging techniques allow noninvasive access to the bony labyrinth and thus, to the hearing system (Spoor, 1993). Quantitative analysis of early hominin specimens revealed that changes are observed in the proportions of the inner ear (notably the oval window and cochlear length) in the hominin lineage that might be related to an increase in low-frequency sensitivity in extant humans as compared to early hominins (Braga et al., 2015). Similarly, the middle ear ossicles (malleus, incus and stapes) can be virtually investigated by the means of high-resolution imaging techniques in fossil hominin taxa for predicting auditory sensitivity levels of the hearing range, and more specifically in the lower frequencies (Stoessel et al., 2016). Interestingly, the audibility of specific frequencies is suggested to impact speech perception (e.g., high-frequencies, Stelmachowicz et al., 2004). In this context, because of the relationship between shape and functions in specific components of the inner ear (e.g., cochlea; Manoussaki et al., 2008), one may imagine possible associations between reconstruction of fossil auditory capabilities and language development.

Additionally, through the identification of genes related to language capacity in extinct hominin species (e.g., FOXP2; Krause et al., 2007) and the description of bones directly involved in speech production in the fossil record (e.g., hyoid bones; Arensburg et al., 1989, 1990), both genetic and anatomical studies undoubtedly constitute invaluable sources of information for evaluating the ability to speak of extinct species (rev. in Lieberman, 2006, 2007). Besides the hyoid bone, the length of the neck and the cranial-base angle are critical for reconstructing the fossil hominin vocal tract (Lieberman, 2007). Interestingly, these structures are preserved in the early hominin fossil record, as illustrated by the recent description of the entire cervical

\section{REFERENCES}

Amunts, K., Schleicher, A., Bürgel, U., Mohlberg, H., Uylings, H. B., and Zilles, K. (1999). Broca's region revisited: cytoarchitecture and intersubject variability. J. Comp. Neurol. 412, 319-341.

Arensburg, B., Schepartz, L. A., Tillier, A. M., Vandermeersch, B., and Rak, Y. (1990). A reappraisal of the anatomical basis for speech in middle Palaeolithic hominids. Am. J. Phys. Anthropol. 83, 137-146. doi: 10.1002/ajpa.1330830202 column of the A. afarensis specimen DIK-1-1 (Ward et al., 2017) or the studies of the basicranial shape and flexion in the most complete A. africanus cranium Sts 5 ("Mrs Ples") (e.g., Ross and Henneberg, 1995; Spoor, 1997), and may contribute to the discussion of the emergence of language.

Similarly, cultural, technical and social contexts certainly played a critical role in the development of language capacities. Indeed, experiments dealing with tool making and functional MRIs revealed the complex pattern of neuronal stimuli in such activities and the intimate relationship with language (Stout et al., 2008), as anticipated by paleoneurological studies (Holloway, 1969, 1981b). Furthermore, these experiments emphasize the importance of learning processes in stone tool manufacture and support the potential influence of inter-individual interactions in the emergence of language ("social brain hypothesis"; Dunbar, 1993). Finally, life history traits should also be considered when searching for the origins of language, particularly since brain plasticity has been revealed to play an important role in the emergence of the human behavior and cognitive traits, including language (rev. in Gómez-Robles and Sherwood, 2016).

Accordingly, a comprehensive approach both in terms of practical investigation (i.e., combining quantification of variation in organization and shape of the endocranial surface) and theoretical background (i.e., integrating biological, social and cultural hypotheses) is essential and unavoidable for understanding the context of the emergence of language. As a whole, research in paleoneurology would significantly benefit from a "holistic" approach to the evolution of the human brain.

\section{AUTHOR CONTRIBUTIONS}

The author confirms being the sole contributor of this work and approved it for publication.

\section{ACKNOWLEDGMENTS}

I am grateful to A. Benítez Burraco and W. Lattanzi for the opportunity of contributing to this special issue. For scientific collaboration and/or discussion, I am especially grateful to $\mathrm{L}$. Bam, F. de Beer, J. Braga, E. Bruner, M. Dierrick, J. Dumoncel, E. Gilissen, J. Heaton, J. Hoffman, K. Jakata, G. Krüger, A. Oettlé, T. Pickering, S. Potze, D. Stratford, F. Thackeray, W. Wendelen, B. Zipfel. The present version greatly benefited from the comments provided by two reviewers. The support of the Claude Leon Foundation and the DST-NRF Centre of Excellence in Palaeosciences (CoE-Pal) towards this research is hereby acknowledged. Opinions expressed and conclusions arrived at, are those of the author and are not necessarily to be attributed to the CoE.

Arensburg, B., Tillier, A. M., Vandermeersch, B., Duday, H., Schepartz, L. A., and Rak, Y. (1989). A Middle Palaeolithic human hyoid bone. Nature 338, 758-760. doi: 10.1038/338758a0

Beaudet, A., and Bruner, E. (in press). A frontal lobe surface analysis in three archaic African human fossils: $\mathrm{OH}$ 9, Buia, and Bodo. C. R. Palevol. doi: 10.1016/j.crpv.2016.12.002

Beaudet, A., Dumoncel, J., Thackeray, J. F., Durrleman, S., Subsol, G., Jessel, J.P., et al. (2014). "Identification of Homo-like features in virtually rendered 
South African australopith endocasts," in The African Human Fossil Record. Available online at: http://www.tahfr.cnrs.fr/?lang=fr

Beaudet, A., Braga, J., de Beer, F., Schillinger, B., Steininger, C., Vodopivec, V., et al. (2016a). Neutron microtomography-based virtual extraction and analysis of a cercopithecoid partial cranium (STS 1039) embedded in a breccia fragment from Sterkfontein Member 4 (South Africa). Am. J. Phys. Anthropol. 159, 737-745. doi: 10.1002/ajpa.22916

Beaudet, A., Dumoncel, J., de Beer, F., Duployer, B., Durrleman, S., Gilissen, E., et al. (2016b). Morphoarchitectural variation in South African fossil cercopithecoid endocasts. J. Hum. Evol. 101, 65-78. doi: 10.1016/j.jhevol. 2016.09.003

Balzeau, A., Holloway, R. L., and Grimaud-Hervé, D. (2014). Variations and asymmetries in regional brain surface in the genus Homo. J. Hum. Evol. 62, 696-706. doi: 10.1016/j.jhevol.2012.03.007

Braga, J., and Thackeray, F. (2007). Diamond Anniversary of Mrs Ples. Johannesburg: Quest.

Braga, J., Loubes, J.-M., Descouens, D., Dumoncel, J., Thackeray, J. F., Kahn, J.-L., et al. (2015). Disproportionate cochlear length in genus Homo shows a high phylogenetic signal during apes' hearing evolution. PLoS ONE 10:e0127780. doi: 10.1371/journal.pone. 0127780

Bruner, E. (2017a). "The fossil evidence of human brain evolution," in Evolution of Nervous Systems Vol. 4, ed J. Kaas (Oxford: Elsevier), 63-92.

Bruner, E. (2017b). Language, paleoneurology, and the fronto-parietal system. Front. Hum. Neurosci. 11:349. doi: 10.3389/fnhum.2017.00349

Carlson, K. J., Stout, D., Jashashvili, T., de Ruiter, D. J., Tafforeau, P., Carlson, K., et al. (2011). The endocast of MH1, Australopithecus sediba. Science 333, 1402. doi: $10.1126 /$ science. 1203922

Connolly, C. J. (1950). External Morphology of the Primate Brain. Springfield, IL: C.C. Thomas.

Dunbar, R. I. M. (1993). Coevolution of neocortical size, group size and language in humans. Behav. Brain Sci. 16, 681-735. doi: 10.1017/S0140525X00032325

Durrleman, S., Pennec, X., Trouvé, A., Ayache, N., and Braga, J. (2012). Comparison of the endocranial ontogenies between chimpanzees and bonobos via temporal regression and spatiotemporal registration. J. Hum. Evol. 62, 74-88. doi: 10.1016/j.jhevol.2011.10.004

Falk, D. (1980a). A reanalysis of the South African australopithecine natural endocasts. Am. J. Phys. Anthropol. 53, 525-539. doi: 10.1002/ajpa.1330530409

Falk, D. (1980b). Hominid brain evolution: the approach from paleoneurology. Yearb. Phys. Anthropol. 23, 93-107. doi: 10.1002/ajpa.1330230507

Falk, D. (1983). Cerebral cortices of East african early hominids. Science 221, 1072-1074. doi: 10.1126/science.221.4615.1072

Falk, D. (2009). The natural endocast of Taung (Australopithecus africanus): insights from the unpublished papers of Raymond Arthur Dart. Am. J. Phys. Anthropol. 140, 49-65. doi: 10.1002/ajpa.21184

Falk, D. (2014). Interpreting sulci on hominin endocasts: old hypotheses and new findings. Front. Hum. Neurosci. 8:134. doi: 10.3389/fnhum.2014.00134

Fischer, C., Operto, G., Laguitton, S., Perrot, M., Denghien, I., Riviere, D., et al. (2012). "Morphologist 2012: the new morphological pipeline of brainVISA," in Proceedings of the 18th Hum. Brain Mapp. Scientific Meeting, NeuroImage (Beijing).

Gómez-Robles, A., and Sherwood, C. C. (2016). Human brain evolution: how the increase of brain plasticity made us a cultural species. Mètode Sci. Stud. J. 89, 71-79. doi: 10.7203/metode.7.7602

Holloway, R. L. (1969). Culture: a human domain. Curr. Anthropol. 10, 395-412. doi: $10.1086 / 201036$

Holloway, R. L. (1978). "The relevance of endocasts for studying primate brain evolution," in Sensory Systems of Primates, ed C. R. Noback (New York, NY: Plenum Press), 181-200.

Holloway, R. L. (1981a). Revisiting the South African Taung australopithecine endocast: the position of the lunate sulcus as determined by the stereoplotting technique. Am. J. Phys. Anthropol. 56, 43-58. doi: 10.1002/ajpa.1330560105

Holloway, R. L. (1981b). Culture, symbols, and human brain evolution: a synthesis. Dialect. Anthropol. 5, 287-303.

Holloway, R. L. (1983). Human paleontological evidence relevant to language behavior. Hum. Neurobiol. 2, 105-114.

Holloway, R. L., Broadfield, D. C., and Yuan, M. S. (2004a). The Human Fossil Record: Brain Endocasts, the Paleoneurological Evidence. Hoboken, NJ: Wiley-Liss.
Holloway, R. L., Clarke, R. J., and Tobias, P. V. (2004b). Posterior lunate sulcus in Australopithecus africanus: was Dart right? C. R. Palevol. 3, 1-7. doi: 10.1016/j.crpv.2003.09.030

Kappers, C. U. A. (1929). The fissures of the frontal lobes of Pithecanthropus erectus Dubois compared with those of Neanderthal men, Homo recens and chimpanzee. Proc. R. Acad. Amsterdam 36, 802-812.

Keller, S. S., Crow, T., Foundas, A., Amunts, K., and Roberts, N. (2009). Broca's area: nomenclature, anatomy, typology and asymmetry. Brain Lang. 109, 29-48. doi: $10.1016 /$ j.bandl.2008.11.005

Kitchell, L. (2017). Is Broca's cap really larger on the left in modern humans? Contradictory evidence via Non-rigid diffeomorphic mapping methods. Am. J. Phys. Anthropol. Suppl. 64:245. doi: 10.1002/ajpa.23210

Krause, J., Lalueza-Fox, C., Orlando, L., Enard, W., Green, R. E., Burbano, H. A., et al. (2007). The derived FOXP2 variant of modern humans was shared with Neandertals. Curr. Biol. 17, 1908-1912. doi: 10.1016/j.cub.2007.10.008

Lieberman, P. (2006). The FOXP2 gene, human cognition and language. Int. Congr. Ser. 1296, 115-126. doi: 10.1016/j.ics.2006.03.039

Lieberman, P. (2007). The evolution of human speech: its anatomical and neural bases. Curr. Anthropol. 48, 39-66. doi: 10.1086/509092

Manoussaki, D., Chadwick, R. S., Ketten, D. R., Arruda, J., Dimitriadis, E. K., and O'Malley, J. T. (2008). The influence of cochlear shape on low-frequency hearing. Proc. Natl. Acad. Sci. U.S.A. 105, 6162-6166. doi: $10.1073 /$ pnas.0710037105

Ross, C., and Henneberg, M. (1995). Basicranial flexion, relative brain size, and facial kyphosis in Homo sapiens and some fossil hominids. Am. J. Phys. Anthropol. 98, 575-593. doi: 10.1002/ajpa.1330980413

Spoor, F. (1993). The Comparative Morphology and Phylogeny of the Human Bony Labyrinth. Ph.D. dissertation, University of Utrech.

Spoor, F. (1997). Basicranial architecture and relative brain size of Sts 5 (Australopithecus africanus) and other Plio-Pleistocene hominids. S. Afr. J. Sci. 93, 182-186.

Stelmachowicz, P. G., Pittman, A. L., Hoover, B. M., Lewis, D. E., and Moeller, M. P. (2004). The importance of high-frequency audibility in the speech and language development of children with hearing loss. Arch. Otolaryngol. Head. Neck Surg. 130, 556-562. doi: 10.1001/archotol.130.5.556

Stoessel, A., Gunz, P., David, R., and Spoor, F. (2016). Comparative anatomy of the middle ear ossicles of extant hominids - Introducing a geometric morphometric protocol. J. Hum. Evol. 91, 1-25. doi: 10.1016/j.jhevol.2015. 10.013

Stout, D., Toth, N., Schick, K., and Chaminade, T. (2008). Neural correlates of early stone age toolmaking: technology, language and cognition in human evolution. Philos. Trans. R. Soc. Lond. B Biol. Sci. 363, 1939-1949. doi: $10.1098 /$ rstb.2008.0001

Tobias, P. V. (1987). The brain of Homo habilis: a new level of organization in cerebral evolution. J. Hum. Evol. 16, 741-761. doi: 10.1016/0047-2484(87)90022-4

Ward, C. V., Nalley, T. K., Spoor, F., Tafforeau, P., and Alemseged, Z. (2017). Thoracic vertebral count and thoracolumbar transition in Australopithecus afarensis. Proc. Natl. Acad. Sci. U.S.A. 114, 6000-6004. doi: 10.1073/pnas.1702229114

Zanolli, C., Schillinger, B., Beaudet, A., Kullmer, O., Macchiarelli, R., Mancini, L., et al. (2017). Exploring the hominin and non-hominin primate dental fossil record with neutron microtomography. Phys. Procedia 88, 109-115. doi: 10.1016/j.phpro.2017.06.014

Zollikofer, C. P. E., and Ponce de León, M. S. (2013). Pandora’s growing box: Inferring the evolution and development of hominin brains from endocasts. Evol. Anthropol. 22, 20-33. doi: 10.1002/evan.21333

Conflict of Interest Statement: The author declares that the research was conducted in the absence of any commercial or financial relationships that could be construed as a potential conflict of interest.

Copyright (๑) 2017 Beaudet. This is an open-access article distributed under the terms of the Creative Commons Attribution License (CC BY). The use, distribution or reproduction in other forums is permitted, provided the original author(s) or licensor are credited and that the original publication in this journal is cited, in accordance with accepted academic practice. No use, distribution or reproduction is permitted which does not comply with these terms. 